\title{
Inhibitory Effects of Cyrtopodion scabrum Extract on Growth of Human Breast and Colorectal Cancer Cells
}

\author{
Ahmad Amiri ${ }^{1}$, Mehdi Namavari ${ }^{2}$, Mojtaba Rashidi ${ }^{1}$, Mohammad Ali \\ Fahmidehkar $^{1}$, Atefeh Seghatoleslam ${ }^{1,3 *}$
}

\begin{abstract}
Breast and colorectal cancers rank high in Iran as causes of mortality. Most of the current treatments are expensive and non-specific. The potential anticancer properties of common home gecko, Cyrtopodion scabrum, were investigated in this study. The effects of $C$. scabrum extract on proliferation, viability and migration of the colorectal cancer (SW-742), breast cancer (MCF-7) and normal (MSC) cell lines were investigated using MTT and in vitro wound healing assay. $\mathrm{IC}_{50}$ values calculated for the extract were $559 \pm 28.9 \mu \mathrm{g} / \mathrm{ml}$ for $\mathrm{MCF}-7$ and $339 \pm 11.3 \mu \mathrm{g} / \mathrm{ml}$ for $\mathrm{SW}-\mathbf{7 4 2}$. No toxic effects on the normal control cells were observed. MCF-7 and SW-742 cell growth was inhibited by $32.6 \%$ and $62 \%$, under optimum conditions, compared to the untreated control cells. The extract also decreased the motility and migration ability of both cancer cell lines, with no significant effects on the normal control cells. Data suggest $C$. scabrum extract as a useful natural resource for targeting cancer cells specifically.
\end{abstract}

Keywords: Anticancer - gecko extract - Cyrtopodion scabrum - proliferation - migration

Asian Pac J Cancer Prev, 16 (2), 565-570

\section{Introduction}

Cancer is one of the widespread and serious diseases in the world. It causes 1 in 8 death cases and is going to be the first cause of death in the world (Society, 2014). Cancer is the third cause of death in Iran with high prevalence and mortality for breast and colorectal cancer in recent decades. Breast cancer is the most prevalent one in women (Taghavi et al., 2012) and the fifth most common cause of death in Iran. The prevalence of colorectal cancer is 3rd in women and 5th in men (Ansari et al., 2006; Cancer Research, 2010; Kolahdoozan et al., 2010; Harirchi et al., 2011). Cancer is uncontrolled growth of abnormal cells which, compared to normal cells, have more proliferation and migration ability. They can invade other sites of the body, far away from their origin and develop tumors, a phenomenon called metastasis (Weinberg, 1994; Todd and Wong, 1999; Pecorine, 2008). There is no definitive treatment for most of cancers. Most of the current available treatments are very expensive, act non-specific and affect both cancerous and non-cancerous tissues. Therefore, finding a safer and inexpensive way of treatment that could prevent cancer cell growth would be very valuable.

Traditional medicine (TM) has a long history in all countries. Nature has been the source of medicinal agents for thousands of years. Many of modern drugs have been isolated from natural resources (Clark, 1996; Harvey,
2008; Jain and Kumar, 2012; Al-Sheddi et al., 2014; Farshori et al., 2014). In the recent decades, there has been increasing interest in the use of TM in both developed and developing countries to find anti-cancer and other remedies for disease. Although most of the materials used in TM are herbal (Yan et al., 2007; Seghatoleslam et al., 2014), zoo therapy, i.e. the use of animals and their derivatives, has been considered as an important part of TM.

Cancer treatment by Islamic herbal medicine and Traditional Iranian Medicine (TIM) dates back to the Golden Age of the Islamic civilization ( $7^{\text {th }}$ to $14^{\text {th }}$ century) when many of the famous Muslim physicians such as Ibn Sina (Avicenna: 980-1037 CE), Al Razi (Rhazes: 865-915 CE) and Al Zahrawi (Abulcasis: 936-1013 AC) studied cancer and applied various medicine and surgical methods (Zaid et al., 2010). Accordingly, in traditional Chinese medicine (TCM) the whole body of Chinese lizard, Gecko Swinhonis Güenther, was used to treat different diseases and also as anti-cancer drug for hundreds of years (Wu et al., 2006; Liu et al., 2008; Wu et al., 2011; Jeong et al., 2012; Song et al., 2012). Several studies in China showed that the extract prepared from this type of gecko shows anti-cancer properties (Wu, et al., 2006; 2011; Liu, et al., 2008; Jeong, et al., 2012; Song, et al., 2012). In Iran, the rough-tailed geckonid lizards of the genus Cyrtopodion consist of 15-16 species. The widely

${ }^{1}$ Department of Biochemistry, Medical School, ${ }^{3}$ Research Center for Traditional Medicine \& History of Medicine / Histomorphometry and Stereology Research Center, Shiraz University of Medical Sciences, ${ }^{2}$ Razi Research Institute of Vaccine and Serum, Shiraz. Branch, Shiraz, Iran *For correspondence: seghatoleslama@yahoo.com 
distributed species is Cyrtopodion scabrum, which is particularly found in southwestern, central, eastern parts and north of Iran (Rastegar-Pouyani et al., 2008; RastegarPouyani et al., 2010). In this study, we investigated the potential anticancer properties of common home gecko, Cyrtopodion scabrum in vitro and compared its effects on the digestive and non-digestive cancer cells. Aiming to understand whether it may selectively suppress cancer cell lines, we applied two candidate cell lines, MCF7(from breast cancer) and SW-742 (from colon cancer) and compared the results with the effects on the normal established cell line, Mesenchymal stem cell (MSC).

\section{Materials and Methods}

\section{Preparation of the aqueous extracts from animal}

Cyrtopodion scabrum was provided from Razi Research Institute of Vaccine \& Serum, Shiraz, Iran. Preparation of the extract was performed according to previous studies (Wu, et al., 2006; Chen et al., 2010) with a slight modification: 12 animals were weighed (30.8 g), cleaned and washed, each time then placed in a mortar, completely crushed and ground by liquid nitrogen and homogenized by a homogenizer (Arthur H Thomas CO. USA) on ice. The homogenate was defatted twice by methanol at room temperature (RT) and boiled three times in distilled water for $2 \mathrm{~h}$. The aqueous homogenate was then centrifuged at $500 \times \mathrm{g}$ for $10 \mathrm{~min}$ at RT to remove the debris. The supernatants were filtered twice by What man filter paper and added to 3 volumes of absolute ethanol. The ethanol precipitate was collected, dissolved in double distilled water, re-filtered, and precipitated by the addition of 3 volumes of ethanol. The precipitation was dissolved in double distilled water (DDW), dialyzed against DDW, and dried by freeze dryer (HetoHolten, Germany). The powder was kept at $-70^{\circ} \mathrm{C}$ until use. Each time the necessary amount of powder was defreezed, weighed and dissolved in RPMI-1640 medium to prepare favorite concentrations of working solutions in all the experiments.

\section{Cell culture}

MCF-7 and SW-742 cell lines were purchased from Pasteur Institute of Iran. Mesenchymal stem cells (MSC) were isolated from umbilical cord obtained from Gynecological surgery unit of Shahid Beheshti hospital, Shiraz, Iran. The establishment of MSC was performed according to Can and Balci (Can and Balci, 2011). The cells were cultured in RPMI 1640 cell culture medium supplemented with 10\% FBS (Fetal bovine serum), 1\% Pen-Strep (Penicillin 100 unit/ml, Streptomycin 100mg/ $\mathrm{ml}$ ) and incubated in a $37^{\circ} \mathrm{C}$ and $5 \% \mathrm{CO}_{2}$ incubator.The number of cells for seeding in the culture plates for each cell line was optimized based on their growth curve. Accordingly, $3 \times 10^{3}$ number of MCF-7and SW-742, and $2.5 \times 10^{3}$ number of MSC were seeded in each well of 96 well-plates separately for the related experiments.

Optimization of the effective dose of $C$. scabrum extract and $\mathrm{IC}_{50}$ calculation

MCF-7, SW-742 and MSC cell lines were cultured in 96-well plates in the complete media supplemented with different concentrations $(100,300,500$ and $700 \mu \mathrm{g}$ gecko powder per ml of medium) of C. scabrum extract. For each concentration, 12-18 wells (repeats) were applied. The plates were then incubated in a cell culture incubator. After adhesion of the cells, the old medium was removed and replaced by $200 \mu 1$ of fresh RPMI1640 media consisting of different concentrations of gecko extract as mentioned above. Negative control wells were received fresh intact medium without treatment. Positive control wells were supplemented with $20 \mu \mathrm{M}$ of 5-FU (KOÇAK FARMA, Turkey) as anti-cancer drug. The plates were incubated at $37^{\circ} \mathrm{C}, 5 \% \mathrm{CO}_{2}$ for $72 \mathrm{~h}$ (see section 2.4 ). The experiments were performed as three independent ones. MTT assay and $\mathrm{IC}_{50}$ calculation were performed for all three cell lines (Sylvester, 2011).

Optimization of the effective incubation time for $C$. scabrum extract

MCF-7, SW-742 and MSC cell lines were cultured in 96-well plates in the complete medium supplemented with optimum concentration of $C$. scabrum extract. 1218 wells (repeats) were applied for each incubation time. Negative control groups underwent no treatment and positive control was supplemented with $20 \mu \mathrm{M} 5$-FU as anti-cancer drug. MTT assay was performed according to standard protocol up to $120 \mathrm{~h}$ for MCF-7, $144 \mathrm{~h}$ for SW-742 and 96h for MSC with the time intervals of $24 \mathrm{~h}$. The different incubation times for the cell lines are reflected by differences in the nature of each one and their differences in growth curve towards plateau. The assays were performed independently in triplicate. Growth rate curves for each cell line were plotted as cell number versus incubation time and compared to each corresponding control untreated wells. Media supplemented with $20 \mu \mathrm{M}$ of 5-FU (KOÇAK FARMA, Turkey), as anti-cancer drug, was applied for positive control wells.

\section{Wound healing assay}

In vitro scratch wound healing assay is based on creation of an artificial gap on a monolayer cells. The cells on the edge of the newly created gap proliferate and will move toward each other to close the gap (Rodriguez et al., 2005; Cory, 2011). To perform this experiment, $4 \times 10^{5}$ MCF-7 cells, $5.5 \times 10^{5}$ SW-742 cells and $3 \times 10^{5}$ MSC were seeded in 6-well 60-mm dishes in duplicate and incubated at $37^{\circ} \mathrm{C}$ to grow about $70 \%$ confluent monolayer. Scratch was created by means of a sampler tips. The plates were gently washed with PBS to remove the detached cells and debris. $2 \mathrm{ml}$ of media containing the optimum concentration of $C$. scabrum extract was added to each well. The negative control wells were incubated with $2 \mathrm{ml}$ of complete media without any additive. The plates were incubated at $37^{\circ} \mathrm{C}$ and the experiments were continued until filling the gap in the control untreated wells. The experiments were repeated as three independent and the images were captured with microscope camera (Olympus, Japan) at different time intervals ( $0 \mathrm{~h}, 24 \mathrm{~h}$ and $48 \mathrm{~h})$ for both cancerous and normal cell lines. Then, the images were compared to the control untreated wells to compare the rate of cells proliferation and migration at the same time. 


\section{Statistical analysis}

Data were analyzed using SPSS 15 software (Chicago, IL, USA) and presented as Mean \pm SEM. To compare the means in groups of different doses, One way ANOVA method was used followed by LSD. In order to see the time dependent effect of $C$. scabrum extract on the proliferation and viability of the cells, Repeated Measures Test were used to compare the means of the groups at different times. To calculate $\mathrm{IC}_{50}$ for each cell line, Curve Expert 1.3 and for plotting the graphs Graph Pad Prism 5 software were used (San Diego, CA, USA).

\section{Results}

Dose dependent effect of $C$. scabrum extract on the cell growth and viability of $M C F-7$ and $S W-742$ cell lines and MSC as control normal cell

The inhibition of MCF-7, SW-742 and MSC cell growth in response to different concentrations of the extract is presented in Figure 1. As shown in the figure, the extract inhibits cancer cells' proliferation in a dose dependent manner. By increasing the concentration up to $500 \mu \mathrm{g} / \mathrm{ml}$ for MCF-7 (Figure 1A) and $700 \mu \mathrm{g} / \mathrm{ml}$ for SW-742 cells (Figure 1B), proliferation decreased and the growth curve reached the plateau. So, 500 or $700 \mu \mathrm{g} /$ $\mathrm{ml}$ was used for all the related experiments as optimum concentrations.IC ${ }_{50}$ values calculated for MCF-7 and SW-742 were $559 \pm 28.9$ and $339 \pm 11.3 \mu \mathrm{g} / \mathrm{ml}$, respectively. Figure $1 C$ revealed that $C$. scabrum extract exhibited a significant inhibitory effect on the proliferation and growth of MSC as normal cells in none of the concentrations applied. The survival percentage of the three cell lines in response to different concentrations of the extract was summarized and compared together in Figure 1D. As shown, no toxic effect on the survival of the normal control cell was observed. For MCF-7 and SW-742 cancer cells,
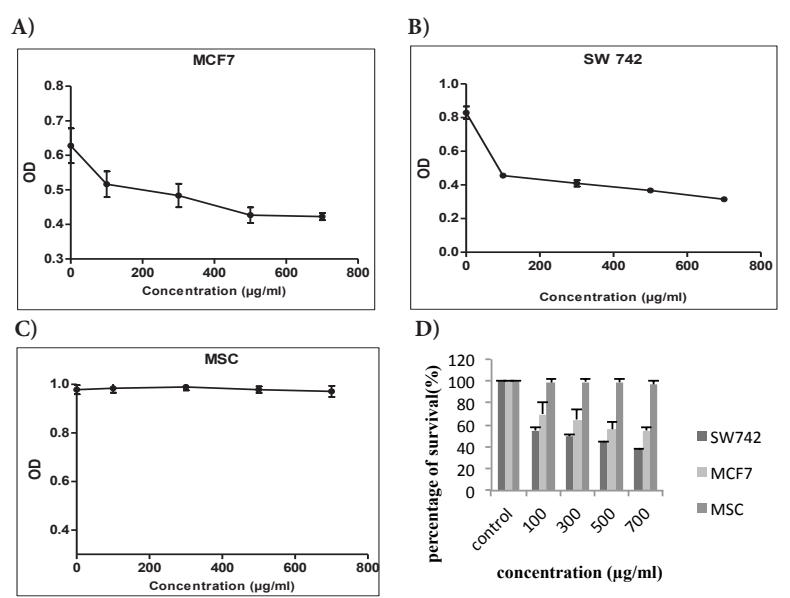

Figure 1. Dose Dependent Effects of $C$. scabrum Extract on the Growth and Viability of MCF-7 (A) SW-742, (B) MSC, (C) Cell Lines. MTT assay was performed for $72 \mathrm{~h}$ at $37^{\circ} \mathrm{C}$ in a $5 \% \mathrm{CO}_{2}$. Optical densities of the live cells were presented as the ratio of different concentrations of the extract. No significant change was observed for MSC normal cells. Data are presented as Mean \pm SEM of the three independent assays for the two cancer cells $(n=3, p<0.01)$ and normal cells $(n=3$, $\mathrm{p}=0.354$ ). Survival percentage of the three cell lines in response to different concentrations of the extract is represented in (D) a decline of $32.6 \%$ and $62 \%$ in the survival was observed at optimum conditions, respectively, when compared to the untreated negative control cells. Therefore, a higher inhibitory effect was observed by $C$. scabrum extract on the proliferation of SW-742 colon cell line compared to the breast cancer cell line.

The effect of different incubation times of C. scabrum extract on proliferation and viability of $M C F-7$ and $S W$ 742 cell lines and MSC as control normal cell

The inhibition of MCF-7, SW-742 and MSC cell growth and proliferation in response to different incubation times at optimum concentration of C. scabrum extract is presented in Figure 2. As shown, the cancer cell line's proliferations were inhibited in a time dependent manner. By increasing the time of incubation, the cells' number increased in both negative untreated control and treatment groups, but the growth rate was suppressed in the treated cell compared to negative control group. The amount of inhibitions for MCF-7 cell lines varied between $22.6 \%$

A)

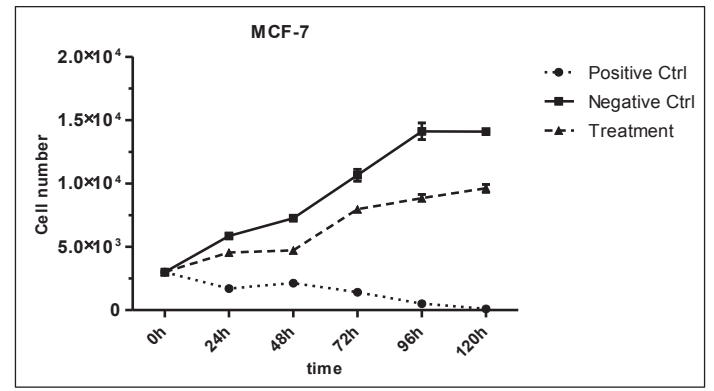

B)

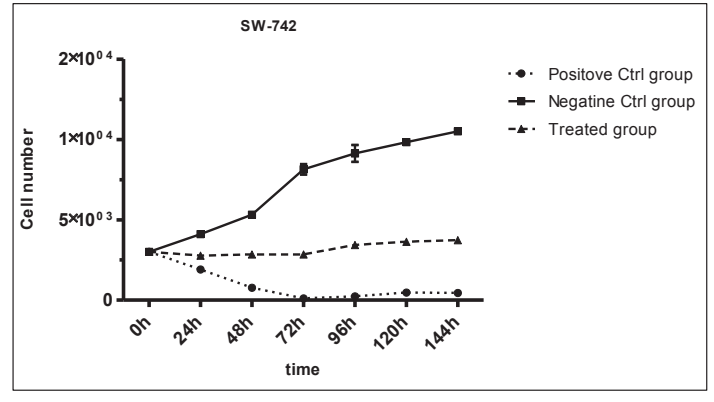

C)

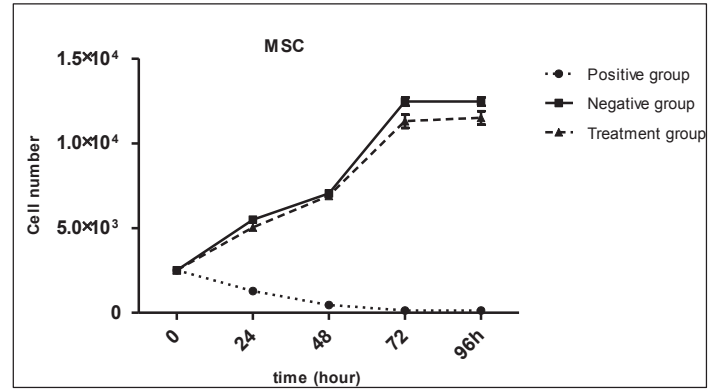

Figure 2. Time Dependent Effect of $C$. scabrum Extract at the Optimum Concentration on the Growth and Viability of MCF-7 (A), SW-742 (B) and MSC Cell Lines (C). Untreated cells were used as negative control. $20 \mu \mathrm{M}$ of 5-FU was used for treatment of positive control cells. Repeated Measures test was used to compare means of the groups at different timeswhere $\mathrm{P}<0.01$ for MCF-7 and SW742 cells, and $\mathrm{P}=0.86$ for MSC. This means that there isn't any significant difference between the cell number in negative untreated control cells and treated group for MSC. Data are presented as Mean $\pm \mathrm{SEM}$ 
at $24 \mathrm{~h}$ and $37.4 \%$ at $96 \mathrm{~h}$ post incubation as minimum and maximum inhibition, respectively (Figure 2A). This amount varied between $32.6 \%$ and $62 \%$ for the incubation times of $24 \mathrm{~h}$ and $72 \mathrm{~h}$, respectively for SW-742 cell line (Figure 2B). These results indicate that colon cell line proliferation is highly suppressed by $C$. scabrum extract at its optimum incubation time and concentration. According to the growth curves of the cancer cells, the growth rates in the treatment groups stayed in the exponential phase up to $72 \mathrm{~h}$, so this time was selected as optimum incubation time for all the experiments. In the positive control group, the cells were treated with 5-FU $20 \mu \mathrm{M}$ as anti-cancer drug and cell proliferation was inhibited strongly as expected. Figure $2 \mathrm{C}$ represents the effect of $C$. scabrum extract on proliferation of MSC as normal control. As shown, no significant effect is observed until $96 \mathrm{hrs}$ where the cells in both negative control and treated groups got completely confluent similarly.

The effect of $C$. scabrum extract on the migration ability of MCF-7, SW-742 and MSC as control normal cell lines

Figure 3 represents the effect of $C$. scabrum extract on the migration rate and ability in proliferation and filling the gap in wound healing assay. This extract at its optimum concentration suppressed cancer cells' migration in a time dependent manner. As shown in Figure 3A, after 24 and $48 \mathrm{~h}$ the differences between treated MCF-7 cells compared to the negative untreated control group are dramatic. The cells in the negative control group filled the gap completely at $48 \mathrm{~h}$ after scratching the monolayer and treating with the extract while in the treated cells group

A)

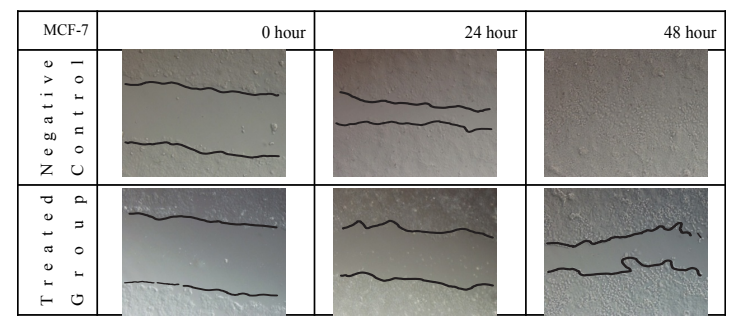

B)

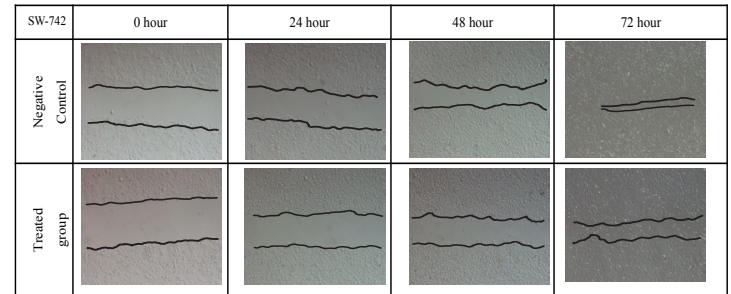

C)

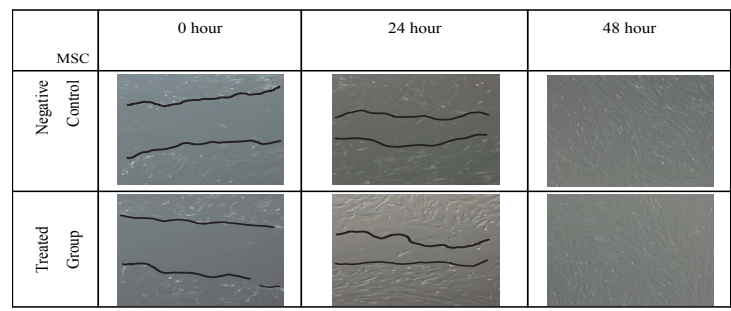

Figure 3. Wound Healing Assay of C. scabrum Extract on the Cell Lines. The suppressing effects of the extract on the migration ability at $24,48 \mathrm{~h}$ and/or $72 \mathrm{~h}$ post scratching and treatment in MCF-7(A) and SW-742 (B)are obvious. As shown, no significant differences are observed for MSC normal cells (C) after treatment with the extract in different time intervals. (Magnification 200X) it reached about half of the initial gap size. Figure 3B represents the response of the SW-742 cells to $C$. scabrum extract. As shown, after $72 \mathrm{~h}$ the cells in the negative control group filled the gap completely while in the treated cells group at $48 \mathrm{~h}$ and $72 \mathrm{~h}$ the difference in filling the gap and migration of the cells is obvious compared to negative control group. Figure $3 \mathrm{C}$ represents the response of the MSC cell lines to the extract. As shown, after $48 \mathrm{~h}$ the cells in both negative control and treated cells group filled the gap completely. So, there were no significant differences in filling the gap and migration of the treated cells compared to the negative control group.

\section{Discussion}

Cancer prevalence and mortality is rising in the whole world. Breast and colorectal cancers are the most cause of cancer death in Iran (Cancer Research, 2010; Kolahdoozan, et al., 2010; Harirchi, et al., 2011). Excessive proliferation and alteration in the migration of cancer cells are the most important causes of tumor progression and death. Therefore, the development of therapeutic agent aiming to prevent cancer cell proliferation and migration is of high importance. Chemotherapy is one of the main strategies for reducing the rate of cancer progression. But a great number of chemotherapeutic agents are cytotoxic that similarly affect normal and neoplastic cells. So, all the current available treatments are not efficient completely and have many side effects. They are also very expensive in most of the cases.

Recently, several studies in China showed that the extract prepared from a species of Chinese lizard, Geckos winhonis Gūenther has anti-cancer properties $(\mathrm{Wu}$, et al., 2006; Wu and Chen, 2006; Yan, et al., 2007; Liu, et al., 2008; Chen, et al., 2010; Wu, et al., 2011; Chen et al., 2012; Jeong, et al., 2012; Song, et al., 2012). We chose one kind of lizard from geckonidae family, Cyrtopodion scabrum, a widely distributed home gecko in southwestern, central and eastern parts of Iran, to investigate its putative anticancer properties.

For this purpose, we selected a breast cancer cell line, MCF-7, as a non-digestive, and a colon cancer cell line, $\mathrm{SW}-742$, as a digestive cell line to perform some in vitro assays. Aiming to explore whether the extract would affect the normal cells similarly or behave selectively on cancer cells, we applied a Mesenchymal stem cell line (MSC) isolated from the umbilical cord and used it as a control normal cell line. The growth curves for each of the cell lines were firstly plotted and the optimum cell numbers to seed in the plates for the experiments were determined. The dependency of the growth and proliferation of all the three cell lines to various incubation times and doses applied were surveyed. Data showed that C. scabrum extract affects both cancer cell lines in a dose and time dependent manner with the optimum effective dose of $500-700 \mu \mathrm{g} / \mathrm{ml}$ of the extract and incubation time of $72 \mathrm{~h} . \mathrm{IC}_{50}$ values of the extract were also determined for both cancer cell lines as $559 \pm 28.9 \mu \mathrm{g} / \mathrm{ml}$ for MCF-7 and $339 \pm 11.3 \mu \mathrm{g} / \mathrm{ml}$ for $\mathrm{SW}-742$, showing the higher sensitivity of colon cancer cell line, SW-742, to the C. scabrum extract, with $62 \%$ down-regulation at the 
optimum condition. Accordingly, 32.6\% down-regulation was observed for MCF-7, the breast cancer cell line. There has been no published report on the effect of gecko extract on the human breast cancer cell lines so far, but the results obtained for SW-742 were in agreement with those of the other reports for Chinese gecko, swinhonis Güenther, extract on the cell lines from the digestive tract including esophageal (Liu, et al., 2008) and hepatic (Wu, et al., 2006; 2011; Chen, et al., 2010) cell lines. However according to our results, $C$. scabrum extract exhibited more significant inhibitory effects on the digestive cell line, SW-742, compared to non-digestive breast cancer cell line, MCF-7. Knowing that gecko is used as an Oriental medicine for cancers in the digestive system, we support the conception of the effectiveness of oral administration of gecko and could guarantee its role in the treatment of carcinoma of the digestive tract.

In the process of cancer development, metastasis is a complex event through which cancer cells migrate from their primary site to other sites and spread in the body. To assess the migration rate and metastasis ability of cancer cells in response to $C$. scabrum extract, in vitro scratch wound healing assay was applied. This assay indicated a significant inhibitory effect of the extract on the migration of MCF-7 and SW-742 cell lines. The most interesting observation in this study was the very negligible inhibitory effect of the extract (less than 3\%) on the proliferation and migration of the normal cell line, MSC, which confirm the selective anti-proliferative and anti-migratory properties of the extract.

Although the exact chemical compositions of the gecko extract are not well-known, some pharmaceutical and structural analyses have shown that it mainly consists of gecko sulfated polysaccharides-polypeptides (GSPP), with a MW of more than $2000 \mathrm{kDa}$ containing 16 types amino acids comprising O-glycopeptide linkages and $8.65 \%$ sulfate group (Chen, et al., 2010). Many sulfated polysaccharides could inhibit cell proliferation and metastasis (Wu and Chen, 2006; Zong et al., 2012). Sulfated polysaccharides, as an important component of the extracellular matrix (ECM) and cell membrane, play an important role in cell proliferation and migration in physiological and pathological conditions (Wu, et al., 2006).

In conclusion, the results of this study indicated the selective anti-cancer properties of $C$. scabrum extract. More studies are needed to determine the anti-cancer compositions of the extract. It is also worthy finding out the pathways and mechanisms that are involved in the inhibition of cell growth and migration by the extract. In vivo studies will also confirm the current results. However, the successful practical use of gecko in TCM and its promising interesting results based on scientific methods suggest its application as an anticancer drug in alternative and complementary medicine for the patients suffering from cancer.

\section{Acknowledgements}

This article was extracted from the MSC thesis written by Ahmad Amiri and financially supported by Shiraz
University of Medical Sciences Grant No.91-6172. We thank Dr A.A. Owji for his help in software and Dr. T. Talaei and Z. Khodabande for their technical help.

\section{References}

Al-Sheddi ES, Farshori NN, Al-Oqail MM, et al (2014). Cytotoxicity of Nigella sativa seed oil and extract against human lung cancer cell line. Asian Pac J Cancer Prev, 15, 983-7.

Ansari R, Mahdavinia M, Sadjadi A, et al (2006). Incidence and age distribution of colorectal cancer in Iran: results of a population-based cancer registry. Cancer Lett, 240, 143-7.

Can A, Balci D (2011). Isolation, culture, and characterization of human umbilical cord stroma-derived mesenchymal stem cells. Methods Mol Biol, 698, 51-62.

Cancer Research TaPI (2010). Cancer statistics. from http:// www.ncii.ir/content.aspx?pid=41.

Chen D, Yao WJ, Zhang XL, et al (2010). Effects of Gekko sulfated polysaccharide-protein complex on human hepatoma SMMC-7721 cells: inhibition of proliferation and migration. J Ethnopharmacol, 127, 702-8.

Chen D, Zhang X, Du Y, et al (2012). Effects of Gekko sulfated polysaccharide-protein complex on the defective biorheological characters of dendritic cells under tumor microenvironment. Cell Biochem Biophys, 62, 193-201.

Clark AM (1996). Natural products as a resource for new drugs. Pharm Res, 13, 1133-44.

Cory G (2011). Scratch-wound assay. Methods Mol Biol, 769, 25-30.

Farshori NN, Al-Sheddi ES, Al-Oqail MM, et al (2014). Cytotoxicity assessments of Portulaca oleracea and Petroselinum sativum seed extracts on human hepatocellular carcinoma cells (HepG2). Asian Pac J Cancer Prev, 15, 6633-8.

Harirchi I, Kolahdoozan S, Karbakhsh M, et al (2011). Twenty years of breast cancer in Iran: downstaging without a formal screening program. Ann Oncol, 22, 93-7.

Harvey AL (2008). Natural products in drug discovery. Drug Discov Today, 13, 894-901.

Jain D, Kumar S (2012). Snake venom: a potent anticancer agent. Asian Pac J Cancer Prev, 13, 4855-60.

Jeong AJ, Chung CN, Kim HJ, et al (2012). Gecko proteins exert anti-tumor effect against cervical cancer cells via PI3-Kinase/Akt pathway. Korean J Physiol Pharmacol, 16, 361-5.

Kolahdoozan S, Sadjadi A, Radmard AR, Khademi H (2010). Five common cancers in Iran. Arch Iran Med, 13, 143-6.

Liu F, Wang JG, Wang SY, et al (2008). Antitumor effect and mechanism of Gecko on human esophageal carcinoma cell lines in vitro and xenografted sarcoma 180 in Kunming mice. World J Gastroenterol, 14, 3990-6.

Pecorine L (2008). Molecular Biology of Cancer: Mechanisms, Targets, and Therapeutics (second ed.): Oxford University Press.

Rastegar-Pouyani N, Kami H, Rajabzadeh M, Shafiei S, Anderson SC (2008). Annotated checklist of amphibians and reptiles of Iran. Iranian J Animal Biosystematics, 4, 7-30.

Rastegar-Pouyani N, Khosravani A, Oraie H (2010). A new record of Cyrtopodion scabrum (Heyden, 1827) from the Caspian sea coastal region, Guilan Province, Northern Iran. ???, 3, 61-3.

Rodriguez LG, Wu X, Guan JL (2005). Wound-healing assay. Methods Mol Biol, 294, 23-9.

Seghatoleslam A, Mashkour N, Namavari M, Azarmehr B, Nejabat M (2014). The potential effects of herbal distillates with hot and cold temperament on cell metabolic activity 
Ahmad Amiri et al

and growth: a preliminary in vitro study. J Pharmaceutical Biomedical Sci, 4, 532-5.

Society AC (2014). Advancing the global fight against cancer. from http://www.cancer.org/aboutus/globalhealth/index.

Song Y, Wang JG, Li RF, et al (2012). Gecko crude peptides induce apoptosis in human liver carcinoma cells in vitro and exert antitumor activity in a mouse ascites $\mathrm{H} 22$ xenograft model. J Biomed Biotechnol, 2012, 743573.

Sylvester PW (2011). Optimization of the tetrazolium dye (MTT) colorimetric assay for cellular growth and viability. Methods Mol Biol, 716, 157-68.

Taghavi A, Fazeli Z, Vahedi M, et al (2012). Increased trend of breast cancer mortality in Iran. Asian Pac J Cancer Prev, 13, 367-70.

Todd R, Wong DT (1999). Oncogenes. Anticancer Res, 19, 4729-46.

Weinberg RA (1994). Oncogenes and tumor suppressor genes. CA Cancer J Clin, 44, 160-70.

Wu X, Chen D, Xie GR (2006). Effects of Gekko sulfated polysaccharide on the proliferation and differentiation of hepatic cancer cell line. Cell Biol Int, 30, 659-64.

Wu XZ, Chen D (2006). Effects of sulfated polysaccharides on tumour biology. West Indian Med J, 55, 270-3.

Wu XZ, Chen D, Han XQ (2011). Anti-migration effects of Gekko sulfated glycopeptide on human hepatoma SMMC7721 cells. Molecules, 16, 4958-70.

Yan ZC, Chen D, Wu XZ, et al (2007). Effects of aqueous extracts of Aconitum carmichaeli, Rhizoma bolbostemmatis, Phytolacca acinosa, Panax notoginseng and Gekko swinhonis Guenther on Bel-7402 cells. World J Gastroenterol, 13, 2743-6.

Zaid H, Rayan A, Said O, Saad B (2010). Cancer treatment by Greco-Arab and islamic herbal medicine. Open Nutraceuticals $J, 3$, DETAIL??

Zong A, Cao H, Wang F (2012). Anticancer polysaccharides from natural resources: a review of recent research. Carbohydr Polym, 90, 1395-410. 